\title{
Anticancer activity of stoppin based on a novel peptide delivery system
}

\author{
YAN-FANG GAO $^{1 *}$, XUE-NI WEI ${ }^{2 *}$, XIAO-LEI YE ${ }^{3 *}$, GUO-BIN WENG $^{4}$, \\ YI-CHEN CHEN $^{3}$, YA-RONG ZHAO ${ }^{2}$ and HUI JI ${ }^{2}$ \\ ${ }^{1}$ Department of Medical Oncology, Weifang People's Hospital, Weifang, Shandong 261040; ${ }^{2}$ School of Pharmacology, \\ China Pharmaceutical University, Nanjing, Jiangsu 210009; ${ }^{3}$ Division of Drugs and Pharmacology, \\ Ningbo Institute of Medical Sciences, Ningbo, Zhejiang 315000; ${ }^{4}$ Department of Urology, \\ Yinzhou Second People's Hospital, Ningbo, Zhejiang 315100, P.R. China
}

Received September 9, 2014; Accepted June 9, 2015

DOI: $10.3892 / \mathrm{mmr} .2015 .4024$

\begin{abstract}
Stoppin (L1) is a newly identified anticancer peptide, which is a potent p53-MDM2/MDMX inhibitor. Due to its limitation in cell delivery efficiency, a new peptide delivery system was developed based on a nucleic acid-polypeptide-liposome complex and its stability and effectiveness in vitro was investigated. The nucleic acid-stoppin-liposome complex was prepared and characterization of the complex was conducted. The stability of the complex was evaluated by enzyme digestion. Following transfection of the A549 cells with the complex, detection of green fluorescent protein (GFP) and luciferase activity was conducted to evaluate transfection efficiency. In addition, the anticancer activity of the complex was determined by 3-(4,5-dimethyl-thiazolyl-2)-2,5 diphenyltetrazolium bromide assay and apoptosis was detected by flow cytometry. The results indicated that the particle size of the complex was $102 \pm 10 \mathrm{~nm}$ and the encapsulation rate was $\sim 100 \%$ when the ratio of liposome, L1 and plasmid was: $4 \mu \mathrm{l}: 1 \mu \mathrm{g}: 2 \mu \mathrm{g}$. The enzyme digestion experiment demonstrated that the complex was resistant to pancreatic and DNA enzyme degradation, indicating that the complex had biological stability. Cell transfection demonstrated that it had a mutual promotion effect on delivery, which could be confirmed by GFP fluorescence and luciferase assay. The cell-killing efficiency of this novel delivery system was three times higher
\end{abstract}

Correspondence to: Professor Guo-Bin Weng, Department of Urology, Yinzhou Second People's Hospital, 1 Qian He Street, Ningbo, Zhejiang 315000, P.R. China

E-mail:wgb@nbyzyy.com

Professor Hui Ji, School of Pharmacy, China Pharmaceutical University, 24 Tongjia Xiang Street Nanjing, Jiangsu 210009, P.R. China

E-mail: huijicpu@163.com

*Contributed equally

Key words: stoppin peptide, plasmids, liposome, lung cancer than with stoppin alone at a low concentration. In conclusion, this novel stoppin peptide delivery system was stable. The nucleic acid-peptide-liposome complex can protect the internal component from the degradation of enzymes, promote entry of the peptide into the cells and enhance the anti-tumor activity of stoppin. Therefore, it is a promising approach for peptide delivery, which can be characterized and visualized using plasmids with GFP or luciferase.

\section{Introduction}

Natural and synthetic peptides are a class of small ligands that have significant potential for cancer therapy. However, designing peptide and protein delivery systems has been a persistent challenge in pharmaceutical research (1). Generally, there are several barriers that must be overcome to achieve successful peptide delivery, including several unfavorable physicochemical properties such as a large molecular size, susceptibility to enzymatic degradation, a short plasma half-life, ion permeability, immunogenicity as well as the tendency to undergo aggregation, adsorption and denaturation $(2,3)$. In order to overcome these barriers, numerous approaches have been investigated for improving the delivery of peptides. For example, certain studies have demonstrated improvement in the enzymatic stability and/or membrane penetration of peptides through chemical modification (4). According to previous studies, numerous cell-penetrating peptides were used for peptide delivery systems (5-7). Other methods, including enzyme inhibitors, conjugation with polyethylene glycol, absorption enhancers and formulation vehicles, have also been used. However, these methods all have limitations, including operational complexity, chemical modification of peptides and limited application.

Endogenous proteins and peptides are important in the regulation and integration of life processes and act with high specificity and potency (1). The previously identified peptide stoppin is a potential anticancer drug. Stoppin (scorpion toxin-derived potent p53-MDM2/MDMX inhibitor) is a 27-residue miniprotein that is derived from the $\mathrm{K}^{+}$channel blocker BmBKTx1 of the Asian scorpion Buthus martensii Karsch (8). Stoppin is able to inhibit p53-MDM2/MDMX 
and efficiently kill tumor cells in a p53-dependent manner (9). The oncoproteins MDM2 and MDMX negatively regulate the activity and stability of the tumor suppressor protein $\mathrm{p} 53$, a cellular process initiated by the binding of the $\mathrm{N}$-terminal domain of MDM2 or MDMX to the transactivation domain of p53 (10). Gene amplification and overexpression of MDM2 and MDMX in numerous tumors confers p53 inactivation and tumor survival, making the two oncoproteins important molecular targets for anticancer therapy. Currently, only Gendicine targets p53 and is applied clinically. However, clinical data have demonstrated that Gendicine can act as an adjuvant therapy with general chemotherapy and radiotherapy, and the predominant route of administration was injection into superficial tumors, such as in nasopharynx cancer (11). Stoppin is a potential p53 target drug. Although numerous approaches have been used to improve the efficiency of peptide delivery, the stability and delivery efficiency of stoppin requires improvement. Considering stoppin binds with arginine, it may be able to combine with plasmids to enhance delivery efficiency.

Although there are peptide delivery systems, issues with the stability and efficiency of delivery remain unsolved. An increasing number of studies are focusing on using liposomes for delivery. For example, successful application of $\mathrm{pH}$-sensitive immunoliposomes has been demonstrated in the delivery of a variety of molecules, including fluorescent dyes, anti-tumor drugs, proteins and DNA (12). However, to the best of our knowledge, there are no studies focusing on the use of plasmids and liposomes to enhance the delivery of peptides. Based on this theory, a novel peptide delivery system was designed based on a nucleic acid-peptide-liposome complex. In the present study, this complex was added to lung cancer cell lines and the stability and efficiency of the new complex was investigated.

\section{Materials and methods}

Complex preparation. Stoppin peptide was synthesized as previously described (12) on Boc-Cys(4-MeBzl)-OCH2-PAM resin using a custom-modified, machine-assisted chemistry according to the published in situ $\mathrm{N}, \mathrm{N}$-diisopropylethylamine neutralization/HBTU activation protocol for Boc solid phase peptide synthesis (8). Peptide structure was determined by mass spectrometry and purity ( 99\%) and assessed by analytical high-performance liquid chromatography (12). Stoppin peptides (L1) were freshly prepared and diluted to appropriate concentrations in distilled water. The plasmid pEGFP-C1 (Clontech Laboratories, Inc., Palo Alto, CA, USA) solution or pGL4.17 (luc2/Neo) vector (Promega Corporation, Madison, WI, USA; $1 \mathrm{mg} / \mathrm{ml}$ in distilled water) was used to obtain a specific weight ratio $(1: 2$ or $2: 1$, peptide to DNA, w/w) and immediately vortexed for $30 \mathrm{sec}$ at room temperature. Subsequently, different quantities of Lipofectamine 2000 (Invitrogen Life Technologies, Carlsbad, CA, USA) were added. Agarose (BioWest, Nuaillé, France) gel electrophoresis was performed to verify the complete complexation of liposome with DNA. Freshly prepared complexes were used in the following experiments.

Characterization of the complex. The particle size and $\zeta$ potential of the complexes were measured using the Zetasizer Nano-ZS (Malvern Instruments, Malvern, UK). The measurement was performed at $25^{\circ} \mathrm{C}$. Each value provided is the average of three measurements. The encapsulation efficiency was investigated by agarose gel electrophoresis. The pGL4.17 (luc2/Neo) vector (1.117 $\mu \mathrm{g} / \mu \mathrm{l}$; Promega Corporation) and peptides (L1; $10 \mathrm{mg} / \mathrm{ml}$ ) were mixed according to the electric charge ratio of peptides and proteins (1:2). Subsequently, different quantities of Lipofectamine 2000 were added. The complexes were mixed with 10X sample buffer and loaded onto the $1 \%$ agarose gel. Electrophoresis was performed using the Tanon EPS 300 system (Tanon Science \& Technology Co., Ltd., Shanghai, China) in $100 \mathrm{v}$ constant voltage for $30 \mathrm{~min}$. The Tanon-2500 Imaging System (Tanon Science \& Technology Co., Ltd.) was used to observe and capture images following electrophoresis.

Stability of the complex against deoxyribonuclease I (DNase I) and trypsin. The complexes were prepared and DNase I (Sigma-Aldrich, St. Louis, MO, USA; 2,000 U/ml) was added and digested for $2 \mathrm{~h}$ at $37^{\circ} \mathrm{C}$. The final concentration of DNase I was $50 \mathrm{U} / \mathrm{g}$ plasmid DNA. Following the experiment, $0.3 \mu \mathrm{l}$ ethylenediaminetetraacetic acid (EDTA; $0.5 \mathrm{M}$; Sigma-Aldrich) was added to the group containing DNase I to suspend the digestion and for the other groups $0.3 \mu 1$ sodium dodecyl sulfate (SDS; 10\%, w/v; Sigma-Aldrich) was added to displace the DNA in the complex. Finally, $0.7 \%$ agarose gel electrophoresis was performed to evaluate the integrity of DNA in the complex. Electrophoresis was performed using the Tanon EPS 300 system at a constant voltage of $100 \mathrm{~V}$ for $90 \mathrm{~min}$ and imaging was performed using the Tanon 2500 Tanon 2500 Gel Imaging system (Tanon Technology Company, Shanghai, China). In addition, the stability of the complex against trypsin (Sigma-Aldrich) was evaluated. The complexes were prepared and digested for $1 \mathrm{~h}$ at $37^{\circ} \mathrm{C}$ following the addition of trypsin. Following that, the complexes were loaded onto 12\% Tris-Tricine gel. The Tanon EPS 300 system was used for electrophoresis at a constant voltage of $80 \mathrm{~V}$ for $90 \mathrm{~min}$. Subsequently, the gel was dyed with Coomassie Brilliant Blue (0.1\% R-250; Sigma-Aldrich) overnight and decolorized with acetic acid-ethanol solution following electrophoresis. The Tanon 2500 Gene Genius Bioimaging System was applied for imaging.

Cell transfection. The human lung cancer cell line A549 was purchased from the Shanghai Institute of Biochemistry and Cell Biology, the Cell Bank of the Chinese Academy of Sciences (Shanghai, China). Cells were cultured in RPMI-1640 medium (Invitrogen Life Technologies, Darmstadt, Germany) and supplemented with $10 \%$ fetal bovine serum (BioWest), $100 \mathrm{U} / \mathrm{ml}$ ampicillin and $100 \mathrm{U} / \mathrm{ml}$ streptomycin (Invitrogen Life Technologies). The two cell cultures were maintained in an atmosphere of $5 \% \mathrm{CO}_{2}$ at $37^{\circ} \mathrm{C}$. A549 cells were seeded in a $35 \mathrm{~mm}$ dish and allowed to grow for $24 \mathrm{~h}$ prior to treatment with the complex. According to a ratio of 1:2:4, polypeptide (D1), plasmid [pEGFP-c1 for GFP, pGL4.17 (luc2/Neo) for luciferase] and Lipofectamine 2000 were mixed and incubated for $20 \mathrm{~min}$. The complex was added into the cell culture and incubated for another $24 \mathrm{~h}$ followed by GFP and luciferase detection. GFP fluorescence was detected on a FACScalibur flow cytometer (Becton-Dickinson, San Jose, CA, USA) through the green fluorescence channel FL1. A GloMax ${ }^{\circledR}$ 20/20 Luminometer (Promega Corporation) was used for the 
detection of fluorescence intensity. Luciferase activity was detected by the dual-luciferase reporter assay system (Promega Corporation).

Cytotoxicity assay. A549 cells were seeded at $5 \times 10^{3}$ cells/well in a 96-well plate (200 $\mu \mathrm{l}$ medium/well) and allowed to grow for $24 \mathrm{~h}$ prior to treatment with the complex. Polypeptides, a complex of peptides and plasmids of different concentrations were added to the cells, with triplicate wells for each group. After another 24 h, 3-(4,5-dimethyl-thiazolyl-2)-2,5 diphenyltetrazolium bromide (MTT; Sigma-Aldrich, Stockholm, Sweden; $5 \mathrm{mg} / \mathrm{ml}$ ) in phosphate-buffered saline was added to the cells $(10 \mu \mathrm{l} /$ well) and the cells were incubated for $4 \mathrm{~h}$ at $37^{\circ} \mathrm{C}$. Supernatant was discarded and $200 \mu \mathrm{l}$ of dimethyl sulfoxide (Sigma-Aldrich) was added to each well to solubilize the MTT-formazan product. Finally, samples were measured on a Multiskan MK3 multi-well spectrophotometer (Thermo Fisher Scientific, Inc., Waltham, MA, USA) at a test wavelength of $560 \mathrm{~nm}$ with a reference wavelength of $650 \mathrm{~nm}$. The growth inhibition rate was calculated using the following formula: Tumor cell growth inhibition rate $(\%)=(1-$ the average absorbance of the complex group / the average absorbance of the control group) x $100 \%$.

Statistical analysis. SPSS 14.0 software (SPSS, Inc., Chicago, IL, USA) was used for statistical analysis and the data are expressed as the mean \pm standard deviation through analysis of variance. Student's t-test was used for determining the significant differences between means and $\mathrm{P}<0.05$ was considered to indicate a statistically significant difference.

\section{Results}

Characterization of the complex. Particle size, $\zeta$ potential and encapsulation efficiency are critical factors in drug delivery. In the present study, the complex was prepared with a particle size of $102 \pm 10 \mathrm{~nm}$ and a polydispersity of 0.20 (Fig. 1A). The $\zeta$ potential in double distilled water ( $\mathrm{pH}$ 6.4) was $6 \pm 2 \mathrm{mV}$ (Fig. 1B). The encapsulation efficiency test demonstrated that the liposome-peptide-plasmid complex was able to package DNA as shown in lanes 5-8. In addition, when the ratio of L1, plasmid and liposome was: $1 \mu \mathrm{g}: 2 \mu \mathrm{g}: 4 \mu \mathrm{l}$, the complex was able to completely package DNA, as shown in lane 5 . However, DNA bands remained visible in lanes 1-4, which contained the plasmid and liposome complex without L1 (Fig. 1C).

Resistance to enzymatic degradation. The stability of the complex was evaluated by an enzyme digestion experiment. To determine the optimum protective effect of the complex with different ratios of plasmids to peptides, three ratios (peptide: plasmid) were compared: 1:1, 1:2 and 2:1. DNase I was used to degrade plasmid, with EDTA to terminate the reaction and SDS to displace the plasmid from the complex. In Fig. 2, for a charge ratio (peptide to plasmid) of 1:1 or 2:1 (lanes 6 and 7 or lanes 9 and 10), the band corresponding to the free form of the oligonucleotide could not be detected. The result indicated that the complex was able to prevent degradation of the plasmid by DNase I. In addition, bands were visible with SDS solution as a positive control (lane 8 and 11),
A

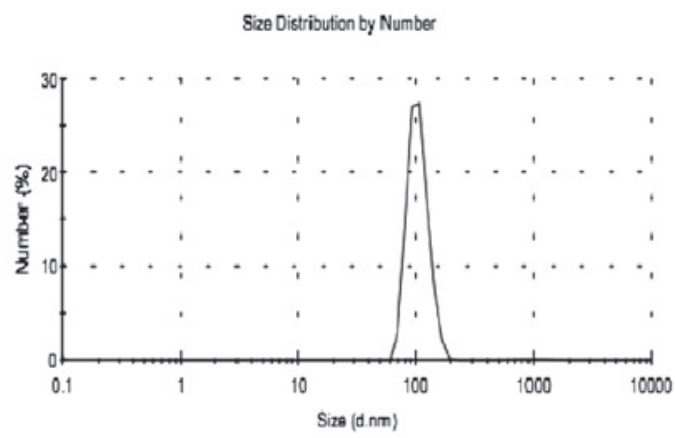

$\mathbf{B}$

3 potential distribution
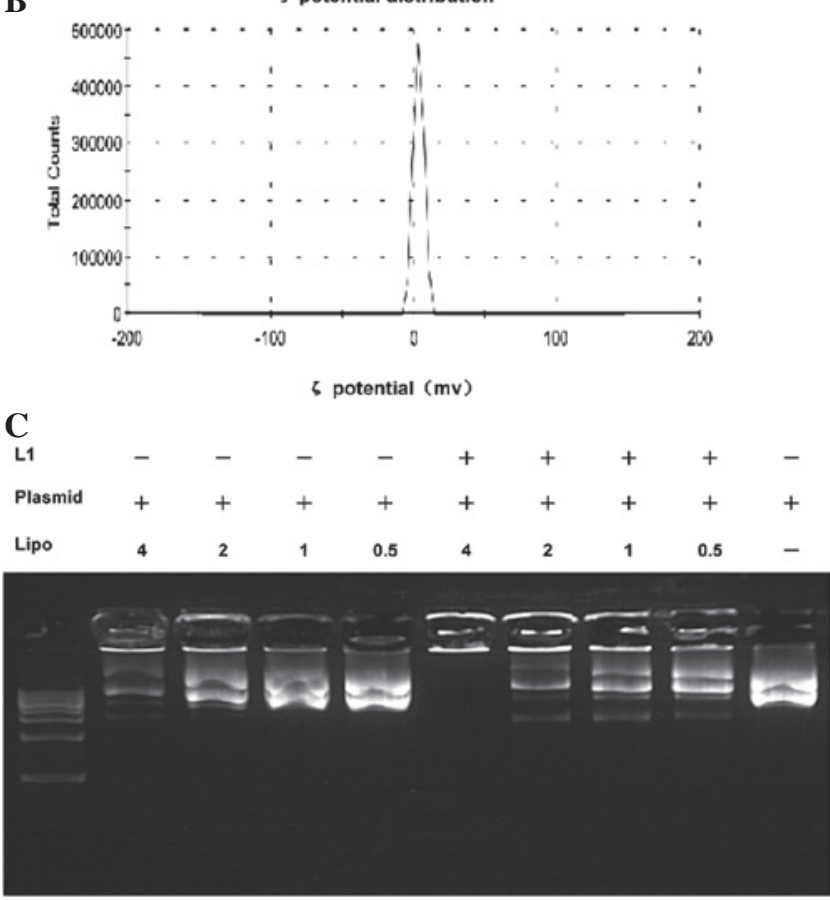

Figure 1. Characterization of the liposome-peptide-plasmid complex. (A) The complex had a particle size of $102 \pm 10 \mathrm{~nm}$ and a polydispersity of 0.20 . (B) $\zeta$ potential in double distilled water ( $\mathrm{pH}$ 6.4). (C) Encapsulation efficiency of the liposome-peptide-plasmid complex. Lanes 1-4 (liposome only) demonstrated DNA bands; lanes 5-8 demonstrated that the DNA was packed and lane 5 demonstrated that the DNA was completely packed.

indicating that SDS solution could be used to verify that the plasmid existed in the complex (Fig. 2A and B). In addition to determining the resistance to DNA enzyme degradation, the stability against trypsin was also evaluated. The complex was digested by trypsin and analyzed by SDS-PAGE. In Fig. 2, stoppin peptide with trypsin demonstrated no bands (lane 2) compared with the untreated peptide (lane 1), which was as a positive control verifying that trypsin was able to react with the peptide. The complexes with different ratios of plasmid to stoppin all demonstrated bands digested by trypsin (lanes 4, 6 and 8). This demonstrated that the peptide part of the complex was not degraded by trypsin. In addition, this also indicated that degradation was prevented to a greater extent when the ratio of peptide to plasmid was 2:1 (lane 7 and 8). Thus, this test confirmed that the complex was able to prevent protein degradation by trypsin (Fig. 2C).

Effect of complex transfection (GFP and luciferase). The complex was transfected into A549 cells to determine the 
A
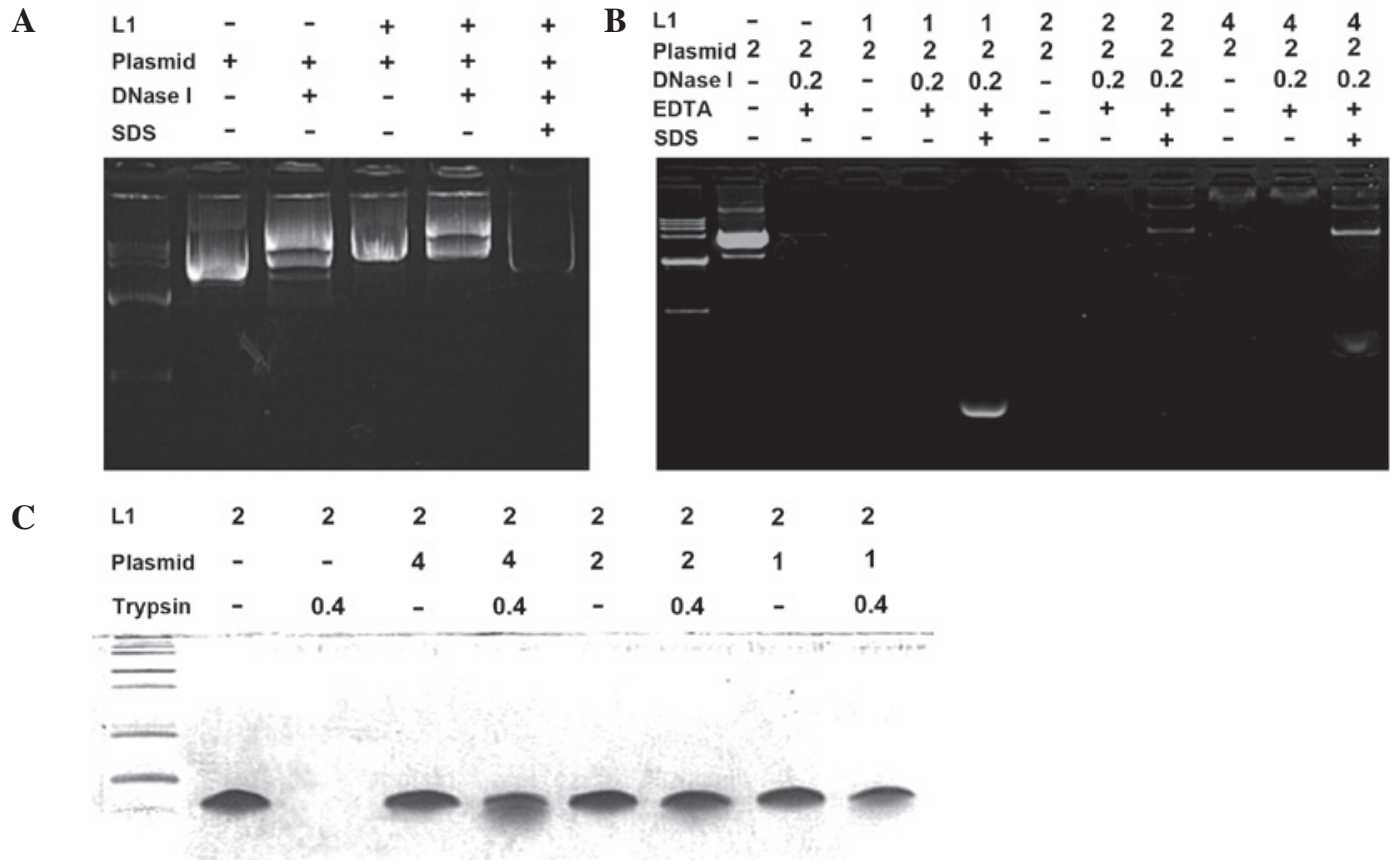

Figure 2. Stability of the complex against enzymatic degradation. (A) SDS solution was used to replace the plasmid in the complex (lane 5) showing the existence of the plasmid in the complex. (B) The result of complexes with different ratio of plasmid to peptide against DNase I .When the ratio of plasmid to peptide was 1:1 or 1:2, in lanes 8 and 11, there were bands, showing complex was able to prevent degradation of the plasmid by DNAse I. (C) Effect of a different ratio of plasmid to peptide on trypsin digestion. Lane 2 , control to verify the reaction of trypsin with peptide. In lanes 4,6 and 8 , the peptide was not degraded by trypsin and the optimum ratio of plasmid to peptide was 1:2.

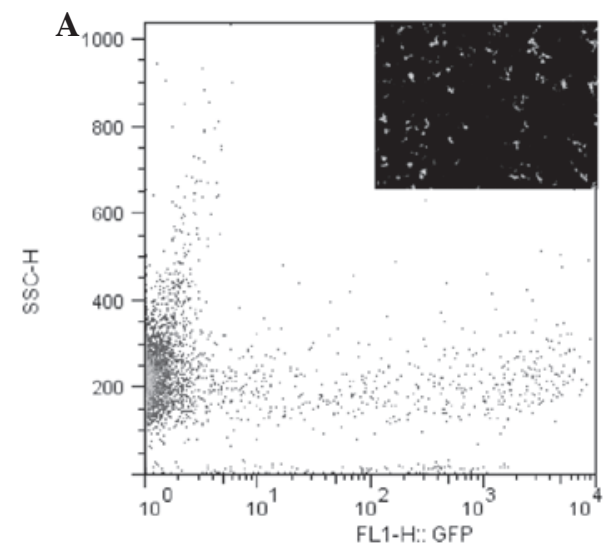

B
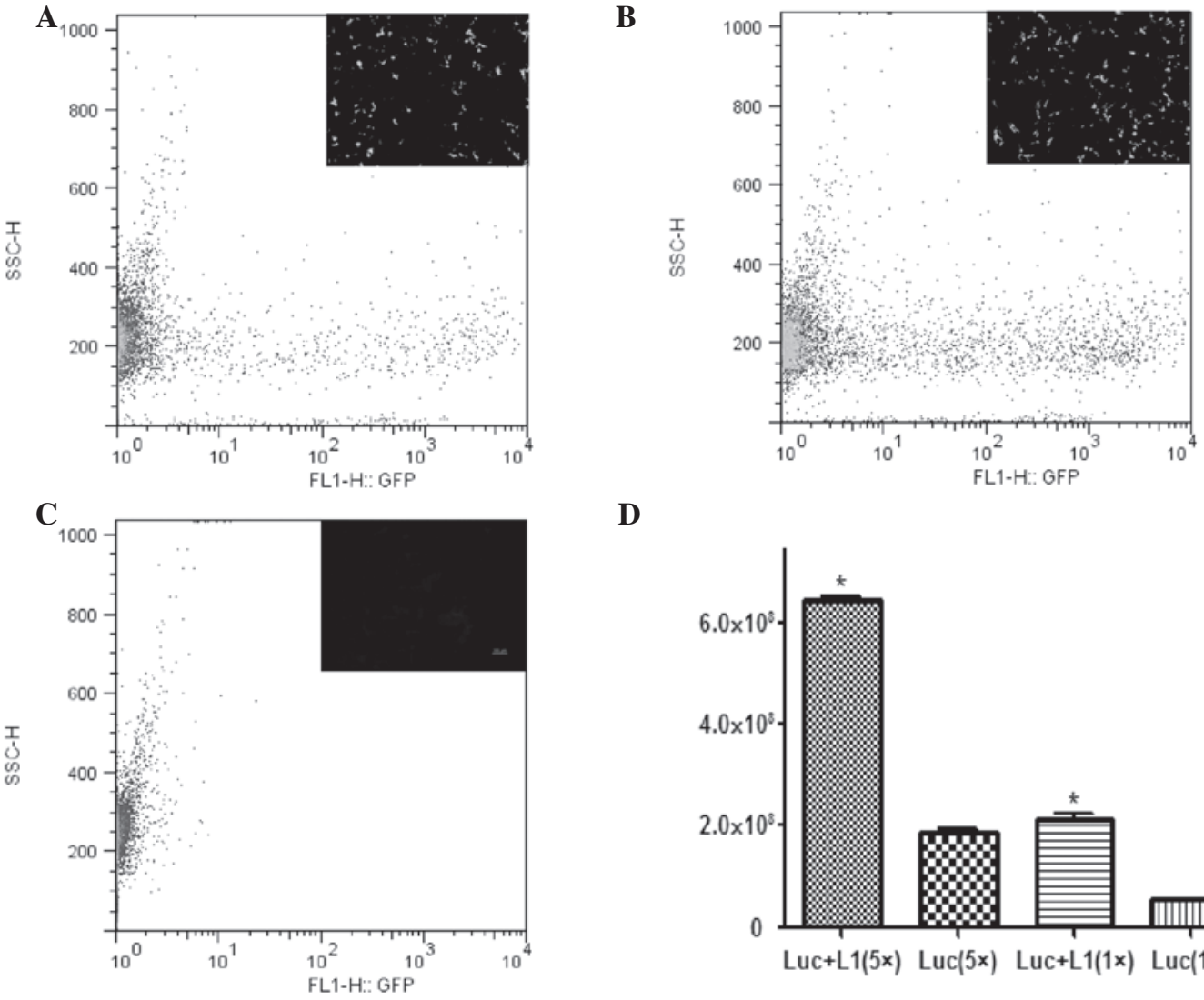

D

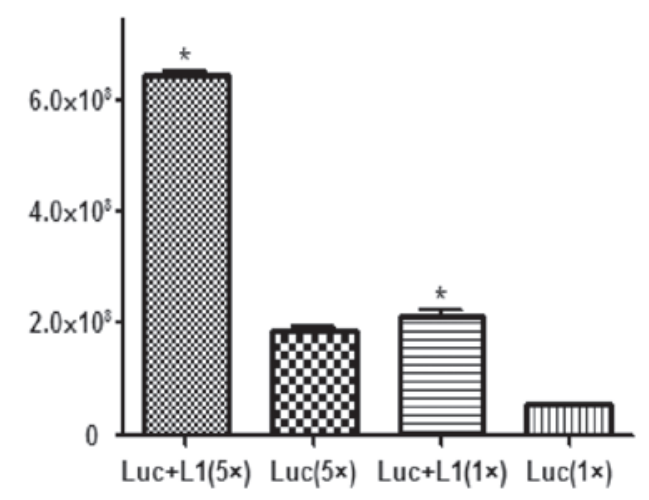

Figure 3. GFP fluorescence and luciferase assay. (A) Detection of GFP expression by flow cytometry. The efficiency of transfection was lower when only GFP was used. (B) The efficiency of transfection and apoptosis was increased significantly when GFP + L1 was used. (C) No fluorescence was detected and apoptosis was lowest when only L1 was used. (D) Luciferase expression level. The efficiency of transfection was up to $6 \times 10^{8}$ with luciferase $+\mathrm{L} 1$ (5X), compared with the result of luciferase only $(5 \mathrm{X}), 2 \times 10^{8}$. With luciferase $+\mathrm{L} 1(1 \mathrm{x})$, the efficiency of transfection was the same as when only luciferase was added. The expression of luciferase in the nucleic acid-polypeptide (L1)-liposome complexes was significantly higher than that of the nucleic acid-liposome complexes $($ ( $\mathrm{P}<0.05$ vs. luciferase only, respectively). GFP, green fluorescent protein. 


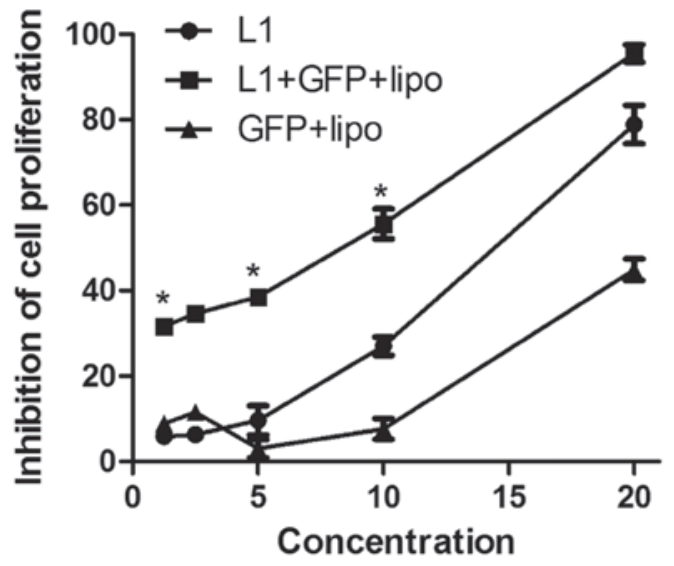

Figure 4. Inhibition of cell proliferation. Inhibition of cell proliferation of the liposome-stoppin-plasmid complex compared with peptide (L1) and stoppin alone $(\mathrm{P}<0.05)$.

delivery efficiency of the peptide-plasmid-liposome complex. Flow cytometry demonstrated that the efficiency of transfection and apoptosis increased significantly when GFP + L1 was used, compared with only GFP or L1 (Fig. 3A-C). The luciferase assay demonstrated that the complex was able to markedly increase the efficiency of transfection up to $6 \times 10^{8}$ using luciferase + L1 (5X), compared with luciferase only (5X; 2x10 ${ }^{8}$ ) (Fig. 3D).

Inhibition of cell proliferation. To demonstrate the tumor-killing activity of the stoppin peptide, an MTT test was used to determine the percent inhibition of cell proliferation. The results demonstrated that the L1-plasmid-lipo complex significantly inhibited cell proliferation. The minimum value was $35 \%$ when using the minimum concentration of the L1-plasmid-lipo complex $(1.25 \mu \mathrm{g} / \mathrm{ml})$ and the maximum value was $\sim 100 \%$ when the concentration was $20 \mu \mathrm{g} / \mathrm{ml}$. However, compared with L1 alone and the plasmid-liposome complex the minimum percentage was $\sim 10 \%$, when the concentration was $1.25 \mu \mathrm{g} / \mathrm{ml}$. In addition, the maximum percent of inhibition of cell proliferation was 70 and $40 \%$ at a concentration of $20 \mu \mathrm{g} / \mathrm{ml}$ for $\mathrm{L} 1$ and the plasmid-liposome complex, respectively (Fig. 4).

\section{Discussion}

Since their discovery and introduction in the mid-1960s by Bangham and Horne (13), liposomes have been proposed as a shuttle to deliver a wide range of encapsulated hydrophilic drugs (14). Certain liposome drugs, including liposomal Paclitaxel and liposomal amphotericin B for injection, have been used in clinical trials. Other studies have also demonstrated that liposome and peptide can be used to promote the delivery of nucleic acids $(15,16)$. Sorgi et al demonstrated that a polycationic peptide and protamine sulfate have the ability to condense plasmid DNA efficiently for delivery into several different types of cells in vitro by several different types of cationic liposomes (17). However, to the best of our knowledge, there are few studies investigating how nucleic acids aid the delivery of peptides. The present study investigated this and demonstrated that the peptide delivery system shows stability and efficiency and thus requires further investigation as it may be clinically value.

Particle size and entrapment efficiency are important factors affecting the clinical therapeutic effects of liposomes and a smaller particle size is favorable for drug delivery (18). The advantage of a smaller particle size is that the rate of drug absorption increases by promoting a more uniform drug distribution (19). A smaller particle size may be obtained through the tight combination of peptide and plasmid. A previous study demonstrated that negatively charged plasmids and positively charged proteins can combine through electrostatic interaction (20). In the present study, the particle size was $102 \pm 10 \mathrm{~nm}$ and this small particle size allows delivery of a higher number of nanoparticles into the cells and thereby enhances the delivery of peptide due to the increased diffusional mobility. Bound with arginine, positively charged stoppin may be able to combine with plasmids through an electrostatic interaction. In addition, the encapsulation rate is high, which can decrease the quantity of liposomes and reduce cell toxicity. Liposome, as a new drug carrier, is also readily available, thus making it possible to establish new peptide delivery systems based on a nucleic acid-polypeptide-liposome complex. The preparation method is simple and DNA is able to efficiently condense peptide.

Enzymatic degradation is one of the main obstacles to peptide delivery. Certain studies have indicated that using protease inhibitors can suppress enzymatic degradation in order to ensure the delivery of polypeptide drugs (21-23). However, the quantity of co-administered inhibitor(s) is unmanageable and un-recordable. The present study demonstrated that the peptide and DNA complex can inhibit degradation by trypsin and DNase I, and protect the integrity of the components. Simultaneously, the complex can promote the entry of peptides and nucleic acids into cells. This is possible since the original exposed enzyme recognition sites are hidden when the peptide and DNA is combined and the shielding effect is present. Furthermore, the system for identifying multiple targets for drug research provides a new approach.

Stoppin competitively inhibits p53-MDM2/MDMX interactions and efficiently kills tumor cells, possibly in a p53-dependent manner (8). To demonstrate the delivery efficiency and tumor-killing activity of the stoppin peptide, transfection experiments and an MTT assay were conducted in the present study. The in vitro data suggested that the complex can increase the delivery efficiency of nucleic acid and peptide. The stoppin peptide has marked anticancer activity. The cell-killing efficiency of nucleic acid-stoppin-liposome was three times higher than with stoppin alone at a low concentration. The maximum percent of inhibition of cell proliferation of the complex was $\sim 100 \%$ when the concentration was $20 \mu \mathrm{g} / \mathrm{ml}$. Furthermore, nucleic acid delivery was determined indirectly by GFP/luciferase activity.

In conclusion, the nucleic acid-peptide-liposome complex delivery system was stable. The peptides can protect nucleic acid from DNaseI degradation, and nucleic acid can protect peptides from trypsin degradation. Peptides can also promote the entry of nucleic acids into cells, and nucleic acid can promote the entry of peptides into cells, enabling stoppin to exert its tumor killing activity. As a target located inside cells, the peptide stoppin requires delivery into cells to exert 
its antitumor effect. This study provides in vitro data, which provides a basis for further in vivo studies of stoppin. At the same time, it provides a new method to identify multiple targets for drug design. The therapeutic effect of this new nucleic acid-polypeptide-liposome complex requires further validation in vivo. Its endocytosis mechanism also requires future investigation. In addition, a 'target' can be applied on the surface of the liposome, so that it can more accurately identify tumor cells to achieve specificity of destruction.

\section{Acknowledgements}

The authors would like to thank Professor Chong Li for guidance with the peptide design.

\section{References}

1. Shaji J and Patole V: Protein and Peptide drug delivery: Oral approaches. Indian J Pharm Sci 70: 269-277, 2008.

2. Saffran M, Kumar GS, Savariar C, Burnham JC, Williams F and Neckers DC: A new approach to the oral administration of insulin and other peptide drugs. Science 233: 1081-1084, 1986.

3. Fix JA: Oral controlled release technology for peptides: Status and future prospects. Pharm Res 13: 1760-1764, 1996.

4. Mahato RI, Narang AS, Thoma L and Miller DD: Emerging trends in oral delivery of peptide and protein drugs. Crit Rev Ther Drug Carrier Syst 20: 153-214, 2003.

5. Lindgren M, Hällbrink M, Prochiantz A and Langel U: Cell-penetrating peptides. Trends Pharmacol Sci 21: 99-103, 2000.

6. Fuchs SM and Raines RT: Pathway for polyarginine entry into mammalian cells. Biochemistry 43: 2438-2444, 2004.

7. Lundin P, Johansson H, Guterstam P, Holm T, Hansen M, Langel U and EL Andaloussi S: Distinct uptake routes of cell-penetrating peptide conjugates. Bioconjug Chem 19: 2535-2542, 2008.

8. Li C, Liu M, Monbo J, Zou G, Li C, Yuan W, Zella D, Lu WY and $\mathrm{Lu} \mathrm{W}$ : Turning a scorpion toxin into an antitumor miniprotein. J Am Chem Soc 130: 13546-13548, 2008.

9. Robinson JA: Design of protein-protein interaction inhibitors based on protein epitope mimetics. Chembiochem 10: 971-973, 2009.
10. Vousden KH and Lane DP: p53 in health and disease. Nat Rev Mol Cell Biol 8: 275-283, 2007.

11. Li, Y, Li B, Li CJ and Li LJ: Key points of basic theories and clinical practice in rAd-p53 (Gendicine ${ }^{\mathrm{TM}}$ ) gene therapy for solid malignant tumors. Expert Opin Biol Ther 15: 437-454, 2015.

12. Geisert EE Jr, Del Mar NA, Owens JL and Holmberg EG: Transfecting neurons and glia in the rat using $\mathrm{pH}$-sensitive immunoliposomes. Neurosci Lett 184: 40-43, 1995.

13. Bangham AD and Horne RW: Negative staining of phospholipids and their structural modification by surface-active agents as observed in the electron microscope. J Mol Biol 8: 660-668, 1964.

14. Accardo A, Aloj L, Aurilio M, Morelli G and Tesauro D: Receptor binding peptides for target-selective delivery of nanoparticles encapsulated drugs. Int J Nanomedicine 9: 1537-1557, 2014

15. Leng Q, Goldgeier L, Zhu J, Cambell P, Ambulos N and Mixson AJ: Histidine-lysine peptides as carriers of nucleic acids. Drug News Perspect 20: 77-86, 2007.

16. Yang ZZ, Li JQ, Wang ZZ, Dong DW and Qi XR: Tumor-targeting dual peptides-modified cationic liposomes for delivery of siRNA and docetaxel to gliomas. Biomaterials 35: 5226-5239, 2014

17. Sorgi FL, Bhattacharya S and Huang L: Protamine sulfate enhances lipid-mediated gene transfer. Gene Ther 4: 961-968, 1997.

18. Immordino ML, Dosio F and Cattel L: Stealth liposomes: Review of the basic science, rationale, and clinical applications, existing and potential. Int J Nanomedicine 1: 297-315, 2006.

19. Yang W, Peters JI and Williams RO 3rd: Inhaled nanoparticles - a current review. Int J Pharm 356: 239-247, 2008.

20. Peer D, Park EJ, Morishita Y, Carman CV and Shimaoka M: Systemic leukocyte-directed siRNA delivery revealing cyclin D1 as an anti-inflammatory target. Science 319: 627-630, 2008.

21. Hutton DA, Pearson JP, Allen A and Foster SN: Mucolysis of the colonic mucus barrier by faecal proteinases: Inhibition by interacting polyacrylate. Clin Sci (Lond) 78: 265-271, 1990.

22. Yamamoto A, Taniguchi T, Rikyuu K, et al: Effects of various protease inhibitors on the intestinal absorption and degradation of insulin in rats. Pharm Res 11: 1496-1500, 1994.

23. Langguth P, Bohner V, Biber J and Merkle HP: Metabolism and transport of the pentapeptide metkephamid by brush-border membrane vesicles of rat intestine. J Pharm Pharmacol 46: 34-40, 1994. 